\title{
Presentation
}

\section{Traditional Herbal Medicine for the Control of Tropical Diseases}

\author{
Kesara Na-Bangchang ${ }^{1 *}$ and Juntra Karbwang ${ }^{2}$ \\ Published online 27 May, 2014
}

\begin{abstract}
Throughout history, traditional herbal medicine has afforded a rich repository of remedies with diverse chemical structures and bioactivities against several health disorders. A common issue of herbal medicine is the limitation of information on their pharmacological activities and their active constituents. Traditionally, the use of herbal medicine has been based on empirical treatment and passed on from generation to generation with information available only in local journals. This prevents several herbal medicines from being developed to their full potential. The presentation will focus on research and development of Atractylodes lancea (Thunb) DC. (AL: family Compositae) as a potential chemotherapeutic for cholangiocarcinoma (CCA), the bile duct cancer commonly found in Southeast Asia. The dried rhizome of AL is a medicinal plant used in Chinese ("Cang Zhu"), Japan ("So-jutsu") and Thai ("Khod-Kha-Mao") traditional medicine for its various pharmacological properties including anticancer, anti-inflammation and antimicrobial activities, activities on central nervous, cardiovascular, and gastrointestinal systems. The major constituents in the essential oils from AL rhizome are $\beta$-eudesmol, hinesol and atractylon. Preliminary investigation has demonstrated its promising anti-CCA activity both in vitro and animal (Opisthorchis viverrini/dimethylnitrosamine-induced CCA in hamsters and CCA - xenografted nude mice) models with high selectivity index comparing with the standard drug, 5-fluorouracil. It also showed virtually no toxicity with only minimal CNS effects on locomotor activity at the maximum dose of $5,000 \mathrm{mg} / \mathrm{kg}$ body weight. Studies are underway to identify active constituent(s) which contribute to anti-CCA activity as well as its pharmacokinetic and pharmacodynamic properties.

The main research interest of my research group is the discovery and development of traditional herbal medicine for the treatment of two important tropical diseases, cholangiocarcinoma and malaria. As the time is quite limited, I am going to give you the summary of the conceptual framework and highlight some important findings which will illustrate how different approaches have been used or applied for the discovery of the promising candidates for these two diseases.
\end{abstract}

Key words: Herbal Medicine, cholangiocarcinoma, Opisthorchis viverrini, Atractylodes lancea (Thumb.) DC., rhizomes, pharmacodynamics, $\beta$-eudesmol

\section{Traditional Herbal Medicine: Malaria Vs. CANCER}

There are quite a number of very good examples of the traditional herbal medicine as a promising source of effective modern medicine in several diseases including cancer and malaria. The good example is artemisinin or qinghaosu. The Chinese herbalists have been using these for more than 2000 years for treatment of many diseases including skin diseases and malaria.

\section{ChOlAngiocarcinoma}

Why cholangiocarcinoma is important? This cancer is adenocarcinoma, which arises from the epithelial cells of the bile duct and this is very common in Asia like in Korea and in China. But, the highest prevalence is in North East of Thailand. You can see that the prevalence in males and female is quite high, about 100,000 population. The major risk of cholangiocarcinoma in most of the countries is the primary sclerosing cholangitis. But in Asia, the major risk factor is liver fluke infection and the major cause of cholangiocarcinoma in Thailand is the consumption of improperly cooked preserved fish that is cyprinid fish species which contains also this fluke, Opisthorchis viverrini, together with the procarcinogen, nitrosamine.

The challenge in the control of cholangiocarcinoma is the lack of early diagnosis too. Patients usually come late,

\footnotetext{
${ }^{1}$ Chulabhorn International College of Medicine, Thammasat University, Thailand

${ }^{2}$ Department of Clinical Product Development, Institute of Tropical Medicine (NEKKEN), Nagasaki University

*Corresponding author:

Tel: +66-8181-11678

E-mail: kesaratmu@icloud.com
} 
advanced stage, which is when applied chemotherapy is quite unsatisfactory. In addition, chemotherapy has been limited by other gut resistance and in addition the adverse effects.

\section{MALARIA}

For malaria, Dr. Howard has already mentioned about the importance of this disease. While waiting for the effective vaccine with hope, chemotherapy remains the key weapon to control malaria. But, unfortunately, Plasmodium falciparum has developed resistance to most of the available anti-malarial drugs. So that's why we need new alternative drugs for both cholangiocarcinoma and malaria.

\section{Screening of 43 Plants Used in Thai Traditional Medicine}

Based on the preliminary screening of about 40 plants used in traditional medicine in Asia in Japan, India, and Thailand, we could select one promising candidate for cholangiocarcinoma and one for malaria. For cholangiocarcinoma, the crude ethanolic extracts of Atractylodes lancea (Thumb.) DC., the rhizomes plant, was shown to exhibit very potent and selective cytotoxicity against human cholangiocarcinoma cell line with quite potent activity and selectivity comparing to the hepatocarcinoma. This plant has been used in Chinese and Thai and Japanese traditional medicine as the rhizomes extract as well as the powder for treatment of several disease, especially digestive disorders and rheumatoid arthritis, night blindness, fever, and cold. In addition, it has been shown to possess several pharmacological actions (Fig. 1).

For malaria, one that was selected was the ethanolic extract of the root of Plumbago indica Linn., which was shown to exhibit potent anti-malarial activity in vitro against both $\mathrm{K} 1\left(\mathrm{IC}_{50}=3.0 \mu \mathrm{g} / \mathrm{ml}\right)$ which is chloroquine resistant and 3D7 $\left(\mathrm{IC}_{50}=6.0 \mu \mathrm{g} / \mathrm{ml}\right)$ which is chloroquine sensitive Plasmodium falciparum clone and with very selective to only malaria parasite (SI $=44.7$ and 26.7, respectively), not to the human cells (Fig. 2).

Plumbago indica Linn. (root) has been used in traditional medicine in many Asian countries for various purposes and the isolated compounds which is bioactive component is plumbagin. It has been shown to possess several pharmacological activities including antibacterial, antiviral, anticancer, antileishmanial, trypanocidal, and insecticidal activities.
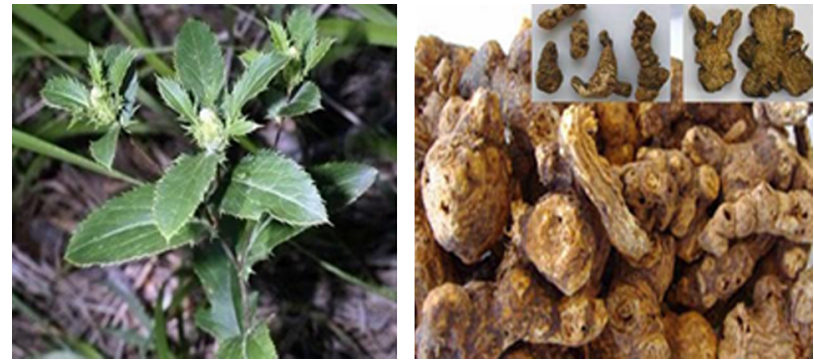

Fig. 1. Atractylodes lancea (Thumb.) DC. (rhizomes).
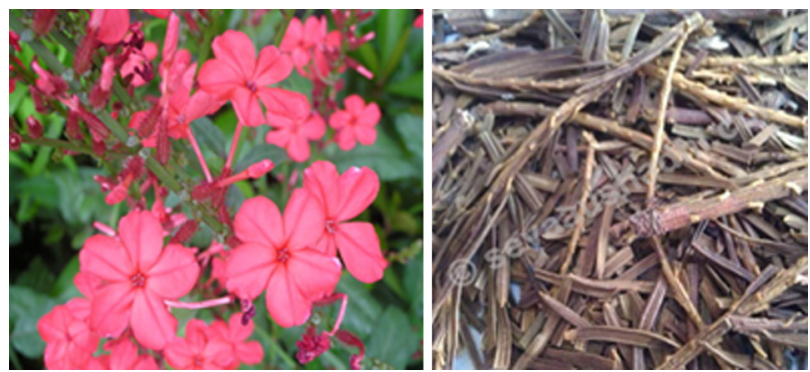

Fig. 2. Plumbago indica Linn. (root).

\section{The Conceptual Framework of the Project}

This is the conceptual framework during the discovery phase of both candidate plants for cholangiocarcinoma and malaria. Initially, the standardized crude ethanolic extract was prepared and initially screened in the in vitro system and the bioactive fractions were identified based on activity-guided fractionation using the various organic solvent with different polarity. Finally, the bioactive compounds from both plants were identified by liquid chromatography mass spectrometry (LCMS/MS) and nuclear magnetic resonance (NMR). The active fractions and isolated compounds were tested both in vitro and in vivo for anti-malarial, anti-cholangiocarcinoma activities, and for the basic pharmacokinetic properties as well as mechanism of actions (Fig. 3).

These in vitro studies were done in parallel with the in vivo study for toxicity and activity and again pharmacokinetics and pharmacological activity. Pharmacokinetic investigation was implemented in parallel with pharmacodynamic investigation to ensure that we get optimal candidates with promising pharmacodynamic and pharmacokinetic properties are obtained. Also, the in silico model using the computer modeling was initially used to predict the pharmacokinetic and pharmacodynamic properties before the in vitro and in vivo studies. 


\section{Conceptual Framework: Pre-clinical Development}

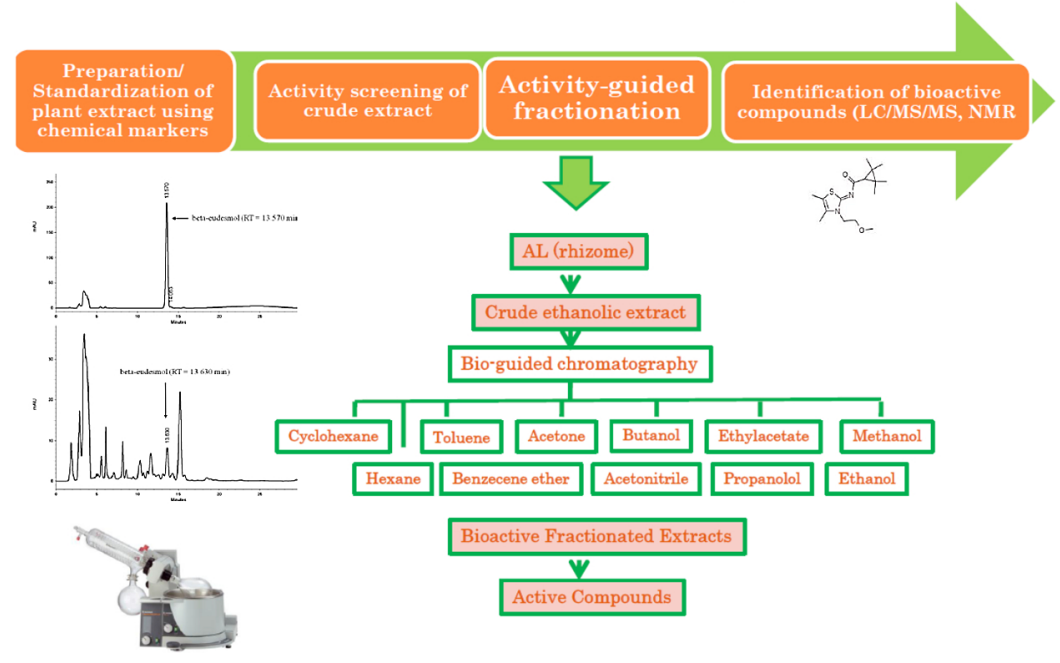

Conceptual Framework:

Pre-clinical Development

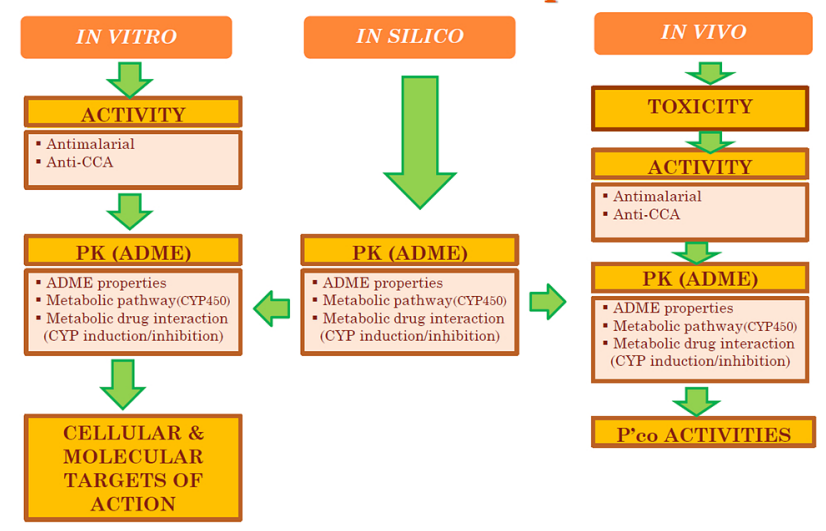

Fig. 3. Conceptual Framework.

\section{Atractylodes lancea (Thumb.) DC.: IN Vitro Anti-CHOLANGIOCARCINOMA ACTIVITY}

First, I will just summarize the results of the anticholangiocarcinoma activity of the crude ethanolic extract of rhizome of Atractylodes lancea (AL). First, we confirm the activity in various in vitro models to support our initial screening, and we found that the extract showed quite potent activity in the three cytotoxic models comparing to the standard drug 5-fluorouracil (5-FU) with potency about 4 times of 5-FU. The selectivity to only the cholangiocarcinoma cell comparing to normal cells is also high comparing to 5-FU. This means that the plant extract is likely to be safer than the 5-FU (Fig. 4).

The extract caused DNA fragmentations which led to

\section{AL: Cytotoxic Activity (CL-6)}

\begin{tabular}{|c|c|c|c|c|}
\hline & $\begin{array}{c}\text { Potencyl } \\
\text { Selectivity }\end{array}$ & MTT & $\begin{array}{c}\text { Calcein- } \\
\text { AM }\end{array}$ & $\begin{array}{c}\text { Hoechst } \\
33342\end{array}$ \\
\hline \multirow{2}{*}{$\mathrm{AL}$} & $\mathrm{IC}_{50}(\mu \mathrm{g} / \mathrm{ml})$ & $\mathbf{2 4 . 0 9}$ & $\mathbf{2 3 . 2 4}$ & $\mathbf{2 7 . 1 6}$ \\
\hline \multirow{2}{*}{$\mathbf{5 - F U}$} & $\mathrm{SI}$ & 8.60 & 10.98 & 10.16 \\
\hline & $\mathbf{I C}_{50}(\boldsymbol{\mu g} / \mathrm{ml})$ & $\mathbf{9 2 . 2 3}$ & $\mathbf{8 9 . 7 5}$ & $\mathbf{9 4 . 6 3}$ \\
\hline & SI & 2.9 & 3.2 & 3.1 \\
\hline
\end{tabular}

Fig. 4. AL cytotoxic activity.

apoptotic cell death. In the clonogenic survival assay, the extract at the higher dose of 100 microgram per milliliter exhibits inhibitory activity on cell survival and proliferation with potency of about two times of 5-FU. In addition, 
in the angiogenesis assay, which will provide the insight into the antiangiogenic activity of this extract, the extract also shows very promising results at the highest dose. The potency is about 3-5 times of the standard drug 5-FU.

Its potency for anti-metastasis was shown in this figure. All dose levels significantly inhibited cell metastasis or cell invasion comparing to 5-FU with potency about 3-4 times of 5-FU [1,2] (Fig. 5).

\section{Atractylodes lancea (Thumb.) DC.: Acute AND Subacute Toxicity Tests and Pharmacological ACTIVITIES}

This is the result of the acute and subacute toxicity test. It shows virtually no toxicity up to the highest recommended dose of 5,000 mg per kilogram body weight in the three species-hamsters, mice, and rats. In addition, the extract showed anti-hypertensive activity, antiinflammatory activity, anti-pyretic, and anti-ulcer activities [3] (Fig. 6).

\section{Atractylodes lancea (Thumb.) DC.: IN VIVo AnTI- CHOLANGIOCARCINOMA ACTIVITY}

We investigated the anti-cholangiocarcinoma activity in xenografted mouse model. Human cholangiocarcinoma cell lines were implanted into this subcutaneous of the nude mice which lack immunity. You can clearly see that the crude extract of AL at all dose levels significantly inhibited the tumor growth comparing to 5-FU standard drug and untreated control. AL at dose levels significantly inhibited tumor growth to about $2 \%$ of the untreated control, while 5-FU inhibited tumor growth to only $70 \%$ of the control (Fig. 7).

In terms of survival time, the extract at all dose levels significantly (double) prolonged the survival time of mice comparing to 5-FU. At all dose levels, the mean survival time was about 80 days comparing to 55 days with 5 -FU and 40 days with untreated control. Very interestingly, results of animal studies supported previous in vitro model on the anti-metastatic activity of the plant extract. The extract inhibited lung metastasis to only about less than 5\% of total lung mass comparing with the untreated control (more than 90\% metastasis) and 5-FU (50\% metastasis) (Fig. 8).

The study is ongoing to confirm the anticholangiocarcinoma of this extract in Opisthorchis viverrini/dimethylnitrosamine-induced cholangiocarcinoma in hamster model, which more closely mimics the natural pathogenesis in human.

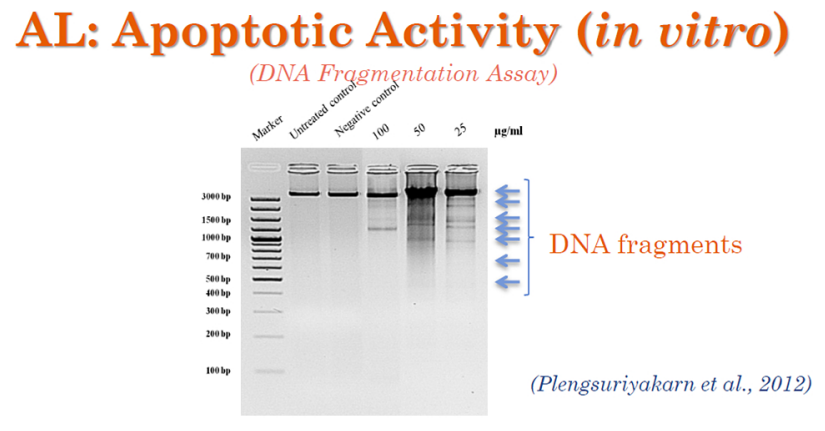

\section{AL: Inhibitory Effect on Cell Survival \& Proliferation (in vitro) \\ (Clonogenic Survival Assay)}

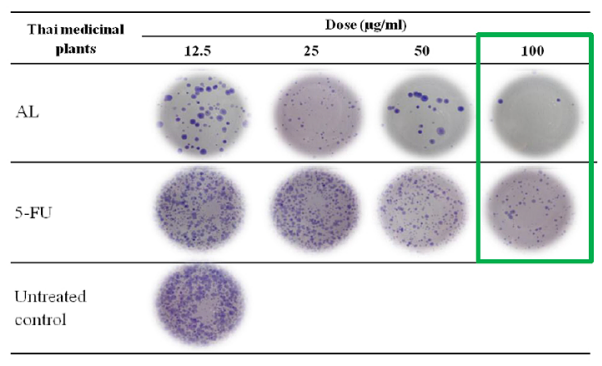

- Potency: 2-fold of 5-FU

(Plengsuriyakarn et al., 2012)

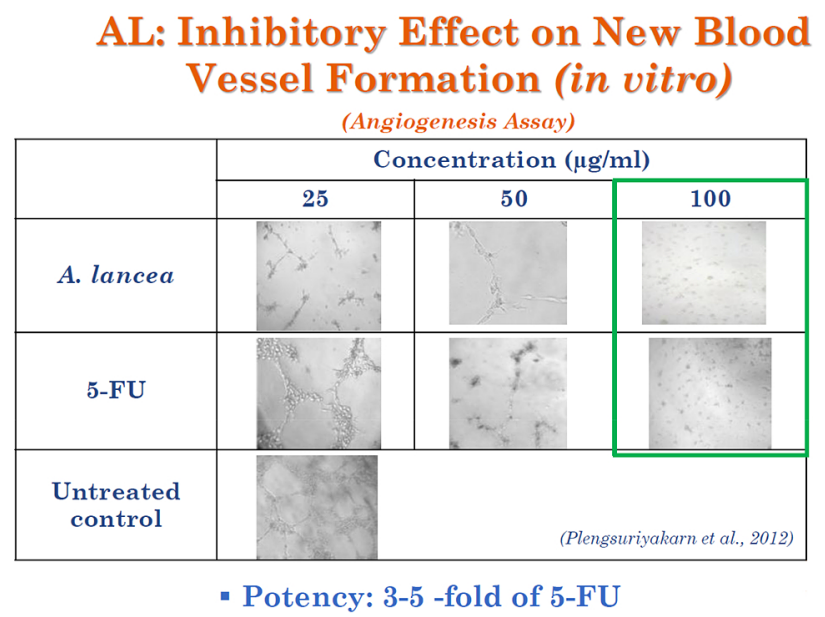

Fig. 5. AL: Toxicity examination.

\section{Atractylodes lancea (Thumb.) DC.: Activity- GUIDED Fractionation AND IsOLATED COMPOUNDS}

Activity-guided fractionation revealed three major isolated compounds from Atractylodes lancea (Thumb.) AC. $\beta$-eudesmol accounts for about $6 \%$ of the total yield, while atractylodin and atractylone account for about $14 \%$ and $9 \%$ of the total yield, respectively. $\beta$-eudesmol exhibi- 


\section{AL: Acute \& Subacute Toxicity}

(OECD, 2004)

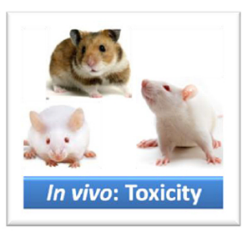

\begin{tabular}{|c|c|c|c|c|c|}
\hline \multicolumn{2}{|c|}{ Hamsters } & \multicolumn{2}{c|}{ BALB/c mice } & \multicolumn{2}{c|}{ Rats } \\
\hline $\begin{array}{c}\text { Maximum } \\
\text { tolerated } \\
\text { dose } \\
\text { (mg/kg body } \\
\text { weight) }\end{array}$ & $\begin{array}{c}\text { Mortality } \\
(\%)\end{array}$ & $\begin{array}{c}\text { Maximum } \\
\text { tolerated } \\
\text { dose } \\
\text { (mg/kg body } \\
\text { weight) }\end{array}$ & $\begin{array}{c}\text { Mortality } \\
(\%)\end{array}$ & $\begin{array}{c}\text { Maximum } \\
\text { tolerated } \\
\text { dose } \\
\text { (mg/kg body } \\
\text { weight) }\end{array}$ & $\begin{array}{c}\text { Mortality } \\
(\%)\end{array}$ \\
\hline 5,000 & 0 & 5,000 & 0 & 5,000 & 0 \\
\hline
\end{tabular}

$\square$ Safety profile of $A$. lancea

$\square$ No significant toxicity except stomach irritation and general CNS depressant signs

Fig. 6. In vivo Toxicity tests.

\section{AL: Anti-CCA Activity in Xenografted Mouse Model \\ Inhibition of Tumor Growth}

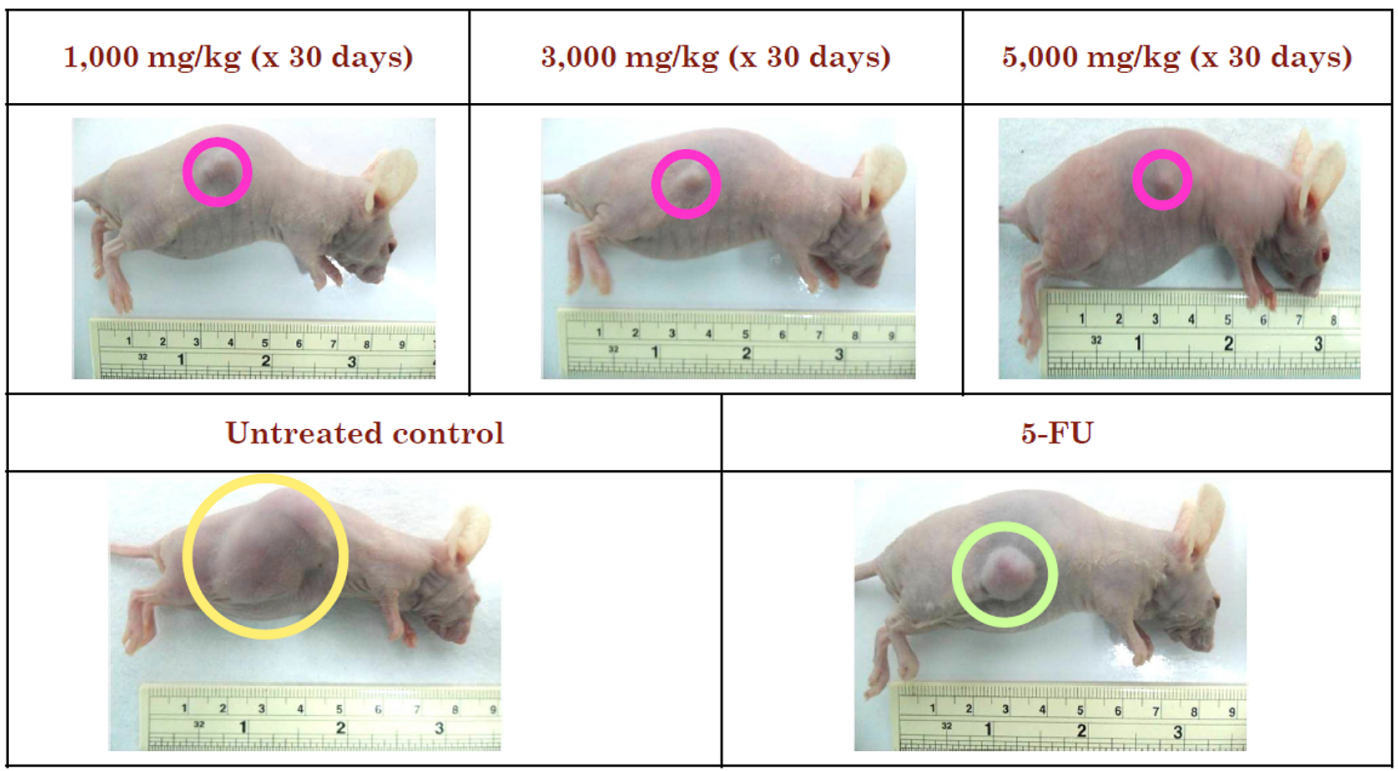

(Plengsuriyakarn et al., 2012)

Fig. 7. In vivo activity.

ted similar potency as the crude extract. Considering quite a low yield in the total crude extract, the potency of activity of this compound was still shown to be to the crude extract. It may suggest that isolated compounds may not be the ideal candidates for further development as anti-CCA drugs, but rather as bioactive fractions or as the crude 


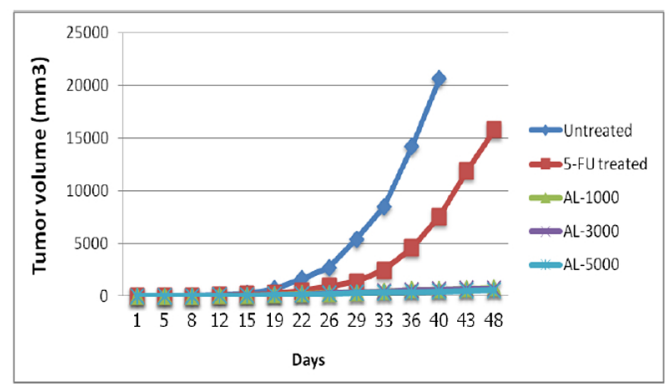

\section{Inhibition of Tumor Growth}

Day 40:

AL at all dose $2.6 \%$ of control

5-FU $76.4 \%$ of control

(Plengsuriyakarn et al., 2012)

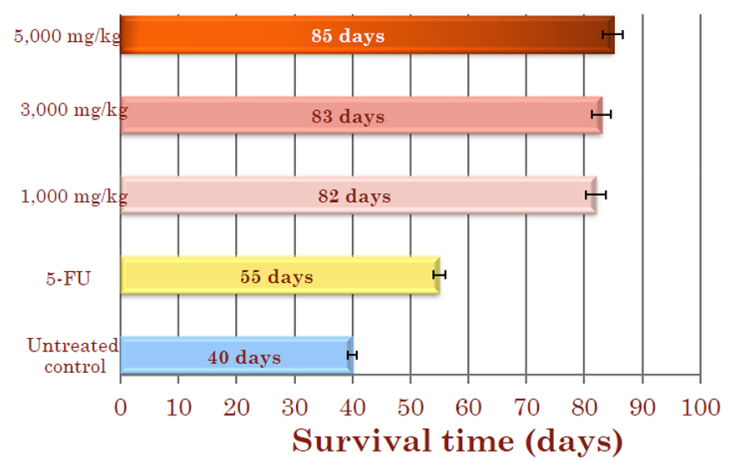

\section{Prolongation of Survival Time}

(Plengsuriyakarn et al., 2012)

\section{Inhibition of \\ Lung Metastasis}

\begin{tabular}{|c|c|c|c|}
\hline Group & $\begin{array}{c}\text { Untreated } \\
\text { control }\end{array}$ & 5 -FU & $\begin{array}{c}\text { A. lancea } \\
(5,000 \mathrm{mg} / \mathrm{kg})\end{array}$ \\
\hline $\begin{array}{c}\text { Histopathology } \\
\text { of lung } \\
\text { metastasis }\end{array}$ & 0 & $50 \%$ & $\leq 5 \%$ \\
\hline $\begin{array}{c}\% \text { Metastasis of } \\
\text { total lung mass }\end{array}$ & $\geq 90 \%$ & $50 \%$ & \\
\hline
\end{tabular}

(Plengsuriyakarn et al., 2012)

Fig. 8. In vivo anti-tumor effects.

extract. This result also confirms the activity of $\beta$ eudesmol in xenografted mouse model. This is the control and this is following treatment with $\beta$-eudesmol 100 milligram per kilogram body weight of the nude mice daily for 30 days. So, the compound significantly inhibited tumor growth as previously been seen with the crude extract, which was also well illustrated when using application of the positron emission tomography, computed tomography (PET-CT) [4] (Fig. 9).
IN VIVO ANTI-CHOLANGIOCARCINOMA OF $\beta$-EUDESMOL

$\beta$-eudesmol significantly inhibited the tumor growth on day 40 to only about $5 \%$ of the untreated control and survival time was longer than 68 days (80 days for the crude extract). For F-5U, the survival time of the nude mice was 55 days and untreated control was about 43 days (Fig. 10). 


\section{Activity-Guided Fractions \& Isolated Compounds}

\section{Cytotoxic Activity (CL-6)}

\begin{tabular}{|c|c|c|c|c|}
\hline & $\begin{array}{l}\text { Potency/ } \\
\text { Selectivity }\end{array}$ & MTT & $\begin{array}{l}\text { Calcein- } \\
\text { AM }\end{array}$ & $\begin{array}{c}\text { Hoechst } \\
33342\end{array}$ \\
\hline \multirow[t]{2}{*}{$\begin{array}{l}\beta \text {-Eudesmol } \\
(6.64 \%)\end{array}$} & $\mathrm{IC}_{50}(\mu \mathrm{g} / \mathrm{ml})$ & 23.76 & 22.02 & 20.11 \\
\hline & SI & 9.20 & 9.88 & 10.44 \\
\hline \multirow{2}{*}{$\begin{array}{l}\text { Atractylodin } \\
(13.92 \%)\end{array}$} & $\mathrm{IC}_{50}(\mu \mathrm{g} / \mathrm{ml})$ & 24.55 & 22.13 & 26.23 \\
\hline & SI & 9.35 & 9.82 & 9.05 \\
\hline \multirow[t]{2}{*}{$\begin{array}{l}\text { Atractylon } \\
(8.63 \%)\end{array}$} & $\mathrm{IC}_{50}(\mu \mathrm{g} / \mathrm{ml})$ & 33.76 & 32.02 & 30.11 \\
\hline & SI & 9.20 & 9.88 & 10.44 \\
\hline
\end{tabular}

(Chaijaroenkul unpublished observation)

Fig. 9. Active compounds.

\section{Pharmacokinetics of $\beta$-eUdesmol}

In terms of the pharmacokinetic properties (with the application of PET using the radiolabel technetium-99m), $\beta$-eudesmol was rapidly absorbed, distributed and excreted within 24 hours. The maximum concentrations in stomach and small intestine were reached within 30 minutes and 2 hours, respectively. All was totally eliminated in urine and feces within 48 hours (Fig. 11).

That result from the in vivo study was supported by the in vitro study in Caco- 2 model (the in vitro model to investigate the permeability of the compounds across human gastrointestinal membrane), so the results show good intestinal permeability of $\beta$-eudesmol, and in addition, we found that it is the substrate of P-glycoprotein which is the efflux protein at the lumen of the intestinal cell membrane. It may indicate that if this drug is coadministered together with other drugs which are also the substrate of P-glycoprotein that will be the potency of pharmacokinetic drug interaction resulting in the increased bioavailability of the co-administered drug (5) (Fig. 12).

In addition, result of in vitro metabolic drug interaction study using hepatic microsomes showed that $\beta$ eudesmol significant inhibited cytochrome P450 2C9 and $1 \mathrm{~A} 2$ activities. Cytochrome P450 2C9 is responsible for the metabolism of some important drugs like antihypoglycemic drug and non-steroidal anti-inflammatory drug. It also induced cytochrome P450 1A2 activity which is mainly metabolized procarcinogen to carcinogen. This may suggest that care should be taken when coadministered the extract with the drugs that are also metabolized by the cytochrome P450 (Fig. 13).

In conclusion, Atractylodes lancea showed promising activity both in terms of pharmacokinetic and pharmacodynamic profiles, but with the propensity of pharmacokinetic drug interaction as it is the substrate of P-glycoprotein, an inhibitor of CYP 2C9 and CYP 1A2, and an inducer of CYP 1A2. Several components in AL may act synergistically for anti-cholangiocarcinoma activity, and we need to identify other active compounds from these plants and also investigate pharmacokinetic and dynamic toxicity profile in animal including the study of cellular and molecular mechanisms of action.

\section{Anti-malarial Activity of PlumbaGo INDICA LiNN.}

The conceptual framework is similar to the discovery of the anti-cholangiocarcinoma, but a little bit different in some approaches. Both plumbagin and the crude extract of Plumbago indica Linn. (root) showed very promising in vivo anti-malarial activity against both chloroquine resistance and chloroquine sensitive $P$. falciparum clones in vitro. However, result of the in vivo study showed very low 


\section{B-Eudesmol: Anti-CCA Activity in Xenografted Mouse Model}
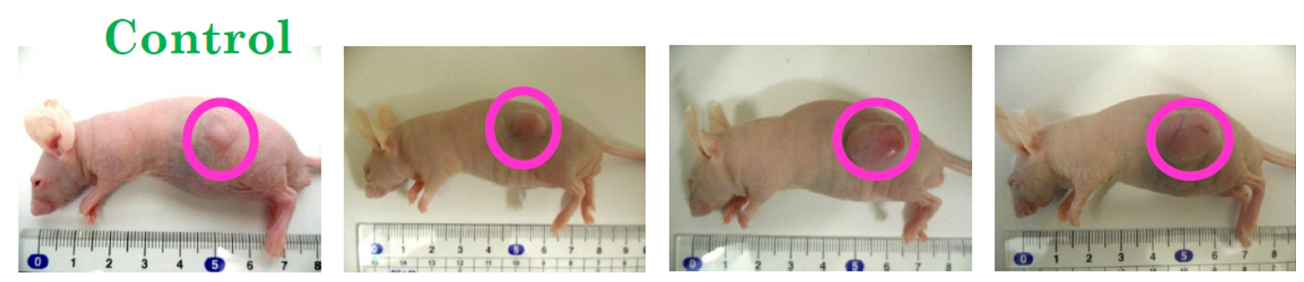

\section{$100 \mathrm{mg} / \mathrm{kg}$ x 30 days (oral)}
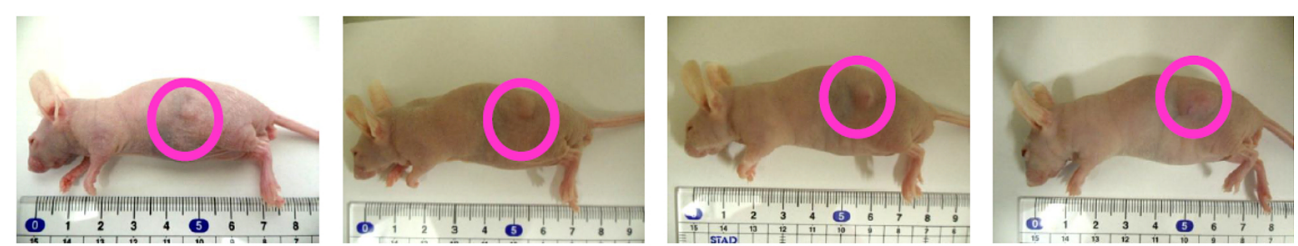

10 days

20 days

30 days

40 days

Daily dosing

(Plengsuriyakarn et al.: P1-38)
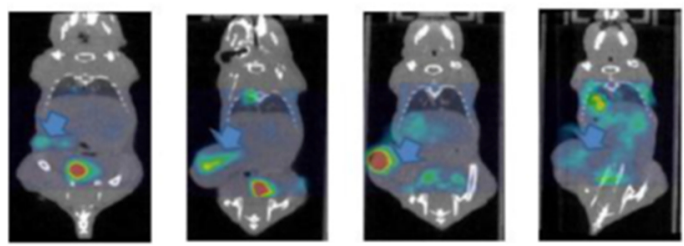

Vehicle-18F-FDG
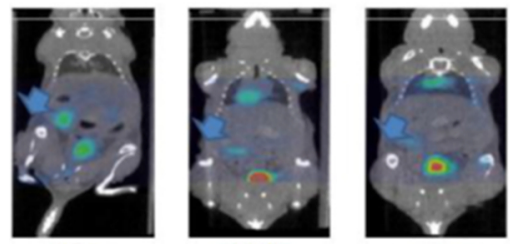

1 days

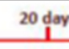

$30 \mathrm{dgns}$

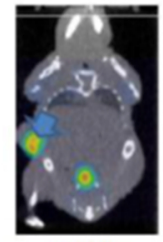

40 deys

$\beta$-Eudesmol-18F-FDG $100 \mathrm{mg} / \mathrm{kg}$

PET-CT

2D imaging

- Survival time:

- $\beta$-Eudesmol > $65 \mathrm{~d}$

- 5-FU $55 \mathrm{~d}$

- Control $43 \mathrm{~d}$

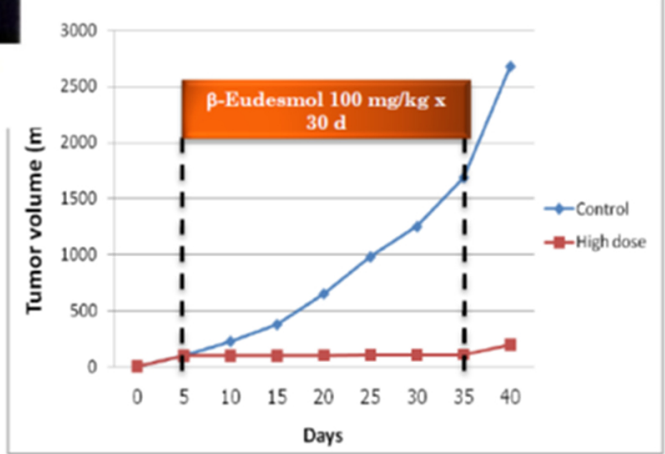

(Plengsuriyakarn et al.: P1-38)

Fig. 10. $\beta$-eudesmol. 
activity. The discrepancy between the in vitro and in vivo activities was also observed in our study during the investigation of its anti-bacterial activity against Staphylococcus aureus. This part is the collaboration with University of Tokyo using the silkworm as a model to test. Pharmacokinetic factor could be the contributing factor. The in silico modeling initially performed to predict the in vivo pharmacokinetic properties of plumbagin. Results of this study together with the in vivo study in silk worm model support that the distribution and metabolism of plumbagin were rapid. Further study in mice model will be performed before going further to human.

\section{LAOTHAVORN JUNTRA AT THE INTRODUCTION}

We try to address the equity in health, which is the traditional medicine. I think in Japan you also use a lot of traditional medicine/herbal medicine as well as in Thailand. So Professor Kesara who is from Thammasat University has been working a lot on the pharmacology and drug metabolism in malaria actually, her experience of more than 25 years working in malaria. But, now, she can see the potential of the herbal medicine in other disease, which of course is tropical diseases, parasitic diseases, which the causative agent is liver fluke. She will be talking about the effect of these herbal medicines. I think she mentioned something about malaria, but also mainly going to be on the cholangiocarcinoma, which is a disease that is very devastating. Mortality rate is practically $100 \%$, but is still neglected.

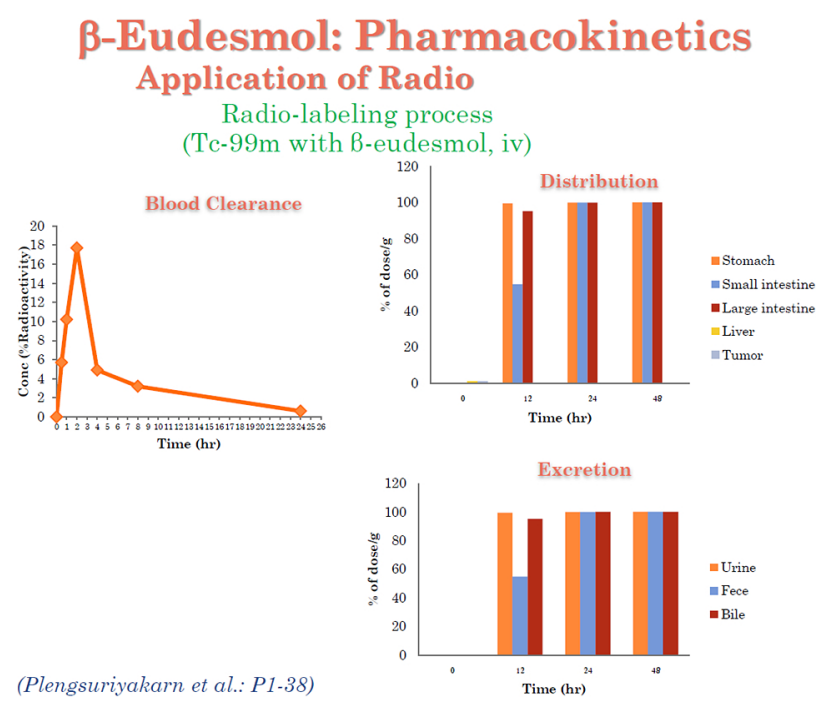

Fig. 11. Pharmacokinetics.

\section{$\beta$-Eudesmol: Human Intestinal Permeability (in vitro)}
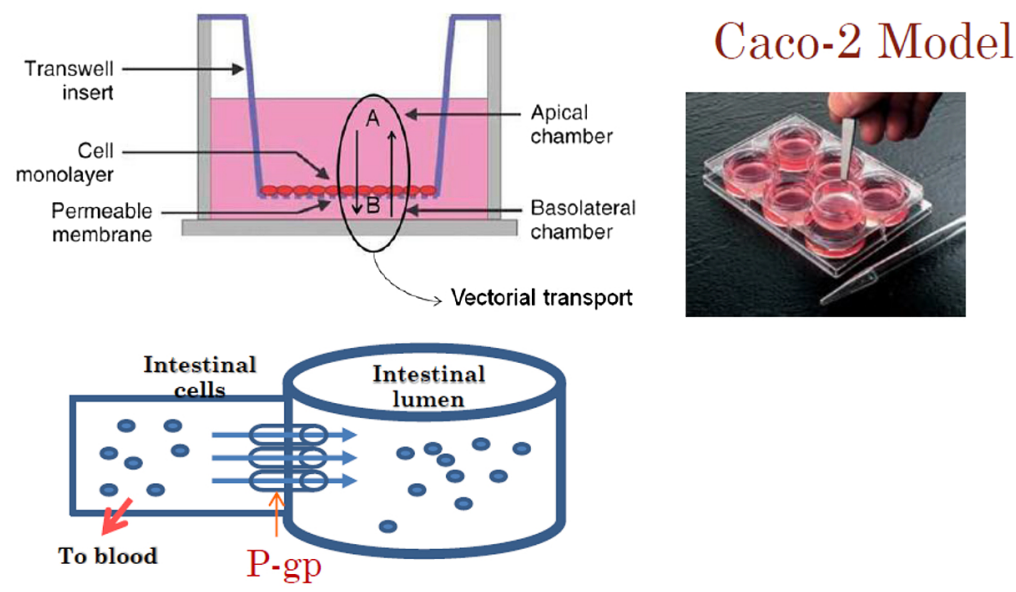

- Good intestinal permeability

- Substrate of P-glycoprotein

Fig. 12. In vitro model. 


\section{ß-Eudesmol: Cytochrome P450 Enzyme Inhibition \& Induction (in vitro)}
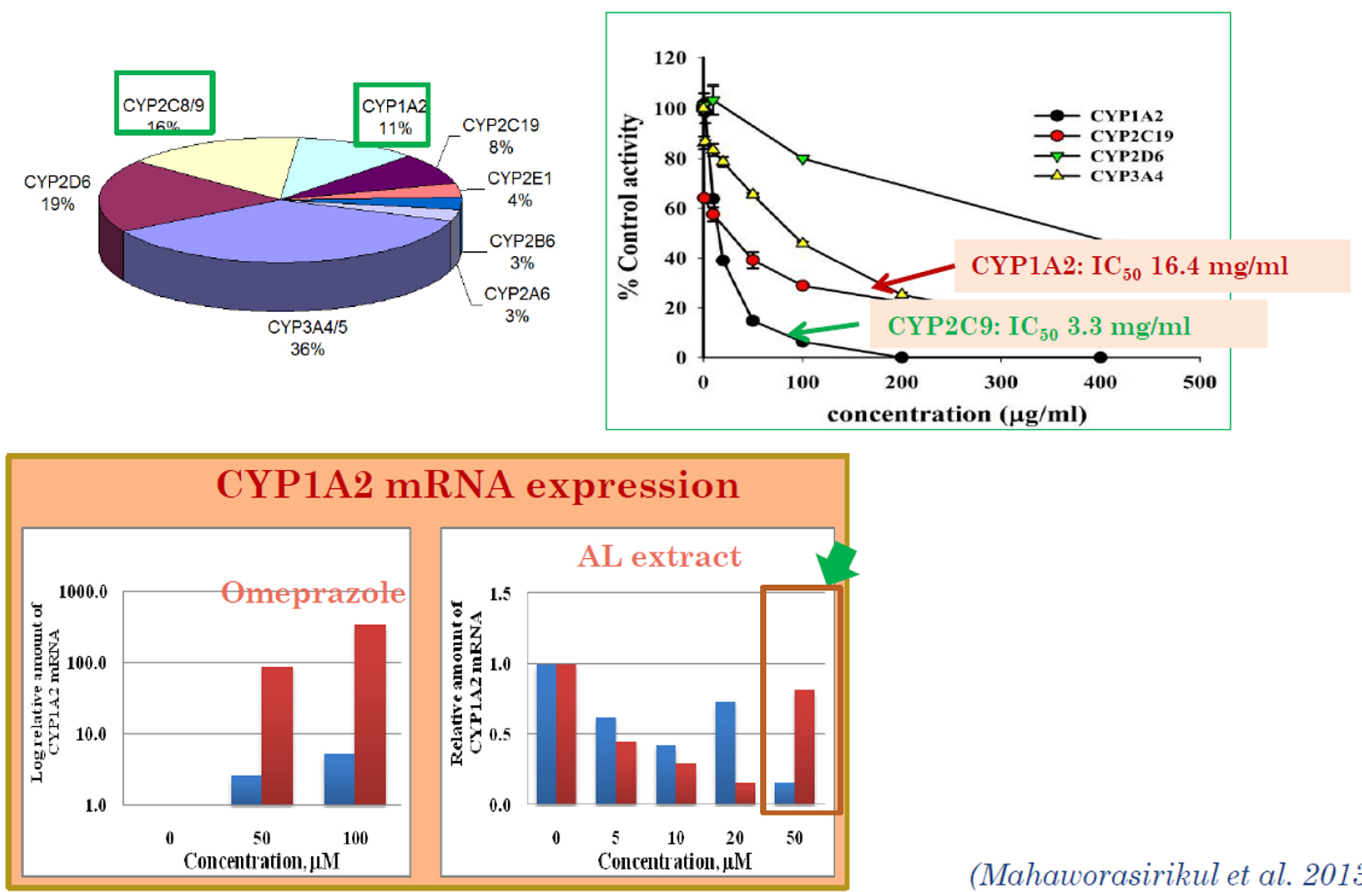

(Mahaworasirikul et al. 2013)

Fig. 13. P450 inhibition and induction in vitro.

\section{Questions AND Discussion}

Laothavorn Juntra Thank you. Is there any question to Professor Kesara?

Male Participant Thank you very much for your nice presentation. I am Bim from Department of Clinical Medicine, Institute of Tropical Medicine, Nagasaki University. My question is like you compared the 5fluorouracil and your medicine AL and with the control, so it is very promising, very, very nice. I just wonder how about having to combine both 5fluorouracil and your medicine versus the control?

Na-Bangchang Kesara We have done that actually and we found that there is antagonistic interaction between 5-FU and this compound, so that is why we tried.

Male Participant Another question is like how this medicine works, like this compound AL in the cell division in the carcinogenesis process, which stage does it belong to, have you already done that study?

Na-Bangchang Kesara You mean which stage of development now? It is still at the discovery phase.

Male Participant Oh, okay. Thank you very much.
Na-Bangchang Kesara We plan for further development to human also.

Male Participant Thank you very much for your nice presentation.

Laothavorn Juntra Any other question so far? Not yet, so we will...

Male Participant Thank you very much for very wonderful talk. I have a question. Just one quick question. Sometimes we are facing the problem about when we are starting the natural product between two countries or three countries, because of the intellectual property of the natural product. Sometimes the government doesn't allow samples to go out to other countries. Do you have some opinion about intellectual property about the natural product, especially when we study by group of the several different countries? For example, if you find very good medicine like this and I want to study with you, but if your government doesn't allow me to bring the substance to Japan, do you have any opinion or idea?

Na-Bangchang Kesara I think Professor Juntra may... She has more experience.

Laothavorn Juntra In Thailand, I think they are propos- 
ing the law as well to bring the stuff across the countries and supply that because, of course, I mean in the past there are some histories to that we lost some of the plants to Japan actually. So, now, there is sort of potential law, but you can get permission actually. You have to have some type of agreement between institutions and then you have to let them know what you are going to be doing. So it is possible. It is not an issue.

Na-Bangchang Kesara Thank you very much Professor.

Laothavorn Juntra Is there anything else? I think traditional medicine is something that we should - this one inspired me a lot about bringing the sources that we have in the country and try to use it. I think it is very effective if we really work on it. But, the weakness of the traditional medicine research is totally different from the vaccine as Dr. Engers mentioned that, oh, there is a rise in the publication about the malaria vaccine. In contrast with the traditional medicine when you do any research, it is very hard to find a journal that will accept your publication. So, the publication is really scattered all around and the knowledge is not really properly disseminated to stimulate other researcher to get involved. Most of the time, the collaboration comes from the personal contact and things like that. I think that's one of the weakness in traditional medicine, but I think it's something that we should be thinking about and try to see whether traditional medicine that's been used for long time can be used for the disease in your own country.

\section{REFERENCES}

1. Plengsuriyakarn T, Eursitthichai V, Labbunruang N, NaBangchang K, Tesana S, Aumarm W, Pongpradit A, Viyanant V. Ultrasonography as a Tool for Monitoring the Development and Progression of Cholangiocarcinoma in Opisthorchis viverrini/Dimethylnitrosamine-Induced Hamsters. Asian Pac J Cancer Prev 2012; 13(1): 87-90.

2. Plengsuriyakarn T, Viyanant V, Eursitthichai V, Picha P, Kupradinant P, Itharat A, Na-Bangchang K. Anticancer activities against cholangiocarcinoma, toxicity and pharmacological activities of Thai medicinal plants in animal models. BMC Complement Altern Med 2012; 12(1): 23.

3. Plengsuriyakarn T, Viyanant V, Eursitthichai V, Itharat A, Na-Bangchang K. In vitro investigations on the potential roles of Thai medicinal plants in treatment of cholangiocarcinoma. Int J Pharm Pharmacol 2012; 2(3): 1-12.

4. Plengsuriyakarn T, Viyanant T, Eursiddhichai V, Tesana S, Chaijaroenkul W, Itharat A, Na-Bangchang K. Cytotoxicity, toxicity, and anticancer activity of zingiber officinale Roscoe against chdangiocarcinoma. Asian Pac J Cancer Prev 2012; 13(9): 4597-4606.

5. Plengsuriyakarm $\mathrm{T}$, Thitapakorn $\mathrm{V}$, Na-Bangchang $\mathrm{K}$, Karbwang J. Thai medicinal plants: potential sources of anti-cholangiocarcinoma drugs. Int J Pharm Pharm 2013; 2(5): 68-82. 